\title{
Short term memory and reaction time: keeping track of several variables'
}

\author{
Robert E. Morin and Andrew Koniek \\ KENT STATE UNIVERSITY
}

\begin{abstract}
Reaction time (RT) and response accuracy depend on the remoteness, in terms of time and number of intervening trials, of a previous response which serves as the stimulus for a present response.
\end{abstract}

\section{Problem}

More than a single correct response was associated with each stimulus in a recent study (Morin \& Forrin, 1963) of response equivocation and RT. As each stimulus occurred $\mathrm{S}$ attempted to select $\mathrm{r}$ a ndo $\mathrm{ml}$ y from among the appropriate response alternatives. Mean RT with 4 stimuli and 2 responses per stimulus was approximately $.25 \mathrm{sec}$. slower than with 2 stimuli and 4 responses per stimulus.

One suggested interpretation of the above result was that the former condition placed a greater tax on short term memory. Attempts to randomize responses to a particular stimulus probably involve efforts to recall previous responses to that stimulus (Tune, 1964). With 4 stimuli the number of trials intervening between the occurrence of a stimulus and its recurrence would, on the average, be greater than with only 2 possible stimuli. Hence the condition with 4 stimuli not only introduced greater opportunities for retroactive effects from intervening responses to other stimuli, but also created a situation in which the information to be recalled was, on the average, temporally more remote in memory. If it is reasonable that the time required to find an item in memory depends on its remoteness (both in terms of time and the number of items intervening since storage), the results of the response equivocation study would be understandable. The present investigation examined the influence of stimulus remoteness upon RT and response accuracy for a task in which performance clearly depended upon memory.

\section{Method}

The Ss were 20 males from an introductory class in psychology at Kent State University. All Ss were tested individually and served in both experimental conditions.

Stimuli were projected from the rear on to a milk glass screen by a Kodak Carousel slide projector. Images were approximately 3 in $x 3$ in and were viewed from $2 \mathrm{ft}$. RT was measured by a Hewlett-Packard electronic counter and was printed on paper tape by a Hewlett-Packard digital recorder. A verbal response by $\mathrm{S}$ activated the voice key, terminated the projected image and initiated the automatic slide changing operation. The interstimulus interval was $.7 \mathrm{sec}$. Verbal responses of $\mathrm{S}$ were recorded by $\mathrm{E}$.

Two responses were associated with each of the four simple geometric figures which served as stimuli (c i r c l e-beet, ball; s qu a re-box, book; tri a ngl ebarb, blade; cros s-badge, brace). The S learned the associations to a criterion of errorless performance during a pretraining period.

The first time a stimulus appeared within a sequence $S$ responded with either of the two associated words. Thereafter the correct response was always the word not given the last time the same stimulus shape was presented. To correctly alternate responses without guessing, it was necessary that $\mathrm{S}$ recall his last response to the same stimulus. The task was one of keeping track of the most recent states (responses) for each of four variables (stimuli).

There were two experimental conditions. In Condition $\mathrm{A}, \mathrm{S}$ responded as rapidly as possible consistent with a high degree of accuracy. In Condition B more time was given to search memory. The $\mathrm{S}$ was instructed not to respond until a jeweled lamp which came on simultaneously with the stimulus had turned off. The lamp remained on for $2 \mathrm{sec}$. and S could take an additional $5 \mathrm{sec}$. to respond. No emphasis was placed upon speed of performance. The order of conditions was counterbalanced.

Four stimulus sequences of length 64 were constructed. Within sequences stimuli occurred equally often as did stimulus digrams and trigrams. Since each sequence was used three times for each $\mathrm{S}$, the 64 test stimuli were preceded by 10 lead-in stimuli selected randomly and separately for each block of trials and each S.

Six blocks of practice were given in each condition. Blocks were separated by 2-min. rests, and a 5-min. rest was interpolated between the two conditions.

\section{Results}

In Fig. 1 mean per cent error, averaged over stimuli and $\mathrm{Ss}$, is plotted as a function of remoteness. A remoteness of $\mathrm{m}$ means that the last response to the same stimulus occurred $\mathrm{m}$ trials earlier. Errors increased markedly as a function of remoteness in both conditions, but performance was significantly better in Condition $\mathrm{B}, \mathrm{F}(1,19)=20.15 ; \mathrm{p}<.001$. At every remoteness Ss made more errors when required to react rapidly (Condition A) than when there was no necessity for speed (Condition B). (The high error rates at a remoteness of 5 are not immediately interpretable and are regarded as spurious.)

Of principal interest is the relationship between RT and stimulus remoteness in Condition $\mathrm{A}$. In the upper half of Fig. 1, one function relating these variables is plotted for correct responses, and another is plotted for errors. In both cases RTs are long, at least .75 sec. 


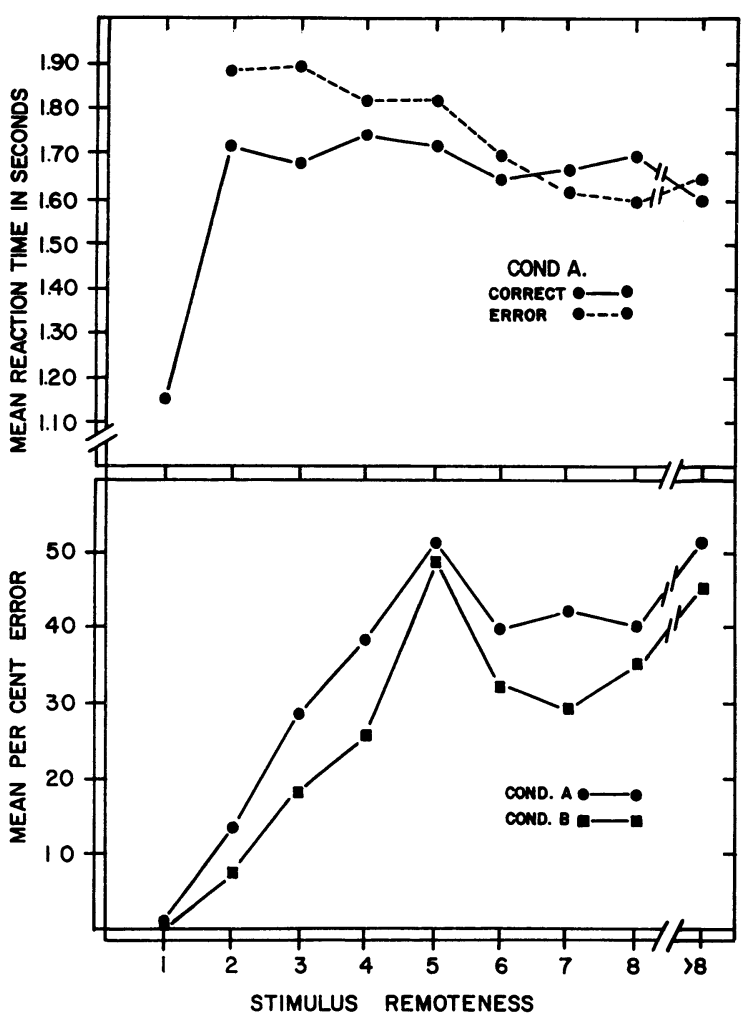

Fig. 1. Mean RT in sec. and mean per cent error as functions of stimulus remoteness.

longer than in the most comparable condition of the response equivocation study cited earlier. Another rather striking feature of the data is that beyond a remoteness of 1 , RT does not increase-the observed slope for correct responses $(-.007 \mathrm{sec} . /$ remoteness $)$ and the slope for errors (-.054 sec./remoteness) are both negative, though only the latter is significantly so, $F(1,19)=41.41$; $\mathrm{p}<.001$. It is only when the response to be recalled was made on the immediately previous trial-at a remoteness of 1-that a markedly lower RT was obtained. (No RT data are plotted for errors at a remoteness of 1 , since performance was error-free for 16 of $20 \mathrm{Ss}$.) Curves for individual $\mathrm{Ss}$, though showing considerable variability in vertical displacement, looked much like the group data. For every $S$ correct responses were most rapid at a remoteness of 1; for 19 of 20 Ss the slope for errors was negative. Individual slopes for correct responses over remotenesses 2-8 were generally close to zero, 13 being negative and 7 positive.

\section{Diseussion}

The results indicate that $\mathrm{RT}$ does depend on the remoteness of the stimulus, but not in a simple fashion. There was not a monotonic increase in the time taken to respond as a function of remoteness. RT was most rapid for a remoteness of 1 , but thereafter the course of the function was approximately flat for correct responses, and was significantly negative for errors.
The data offer some support for the hypothesis offered to explain longer RTs with 4 stimuli than with 2 stimuli when the task is randomization of responses. In a random sequence of 4 equally likely stimuli, a stimulus recurs at a remoteness of 1 approximately .25 of the time; with 2 stimuli the comparable figure is .50 . Given that memory is important to the randomization task, the 2-stimulus condition should benefit more from the much faster reactions at a remoteness of 1 .

At the same time, the data suggest that memory-at least memory for the last response to the same stimulus - was not all-important to the Ss in the response equivocation study. RTs are much shorter when the task is randomization than when it is the remembering of a previous response. This result suggests that in the randomization task Ss must, at least occasionally, react in less than some minimum time necessary for recall of the previous response to the same stimulus.

The findings with respect to RT and remoteness recommend some interesting possibilities. The negative slope for errors indicates that Ss do identify trials on which they might expect to respond correctly, and furthermore, that they spend more time searching memory on these trials if uncertain about the response. To illustrate, if a square is presented Smay remember that he last saw the square only 2 or 3 trials back in the stimulus series, yet he may be unable to recall his response. Under such circumstances he is apparently willing to spend more time searching memory, perhaps because additional time spent searching is more frequently rewarded when an item is temporally not too remote.

The findings with respect to errors have implications for the interpretation of the RT-remoteness data for correct responses since the latter measure includes some chance successes. If the component contributed by chance successes-which should by itself have an RTremoteness slope similar to that for errors-were removed from the curve for correct responses, then the latter function might well have a slightly positive slope. The exact contribution of this component is difficult to assess since there is no assurance that choices for trials on which the $\mathrm{S}$ was uncertain resulted in as many successes as failures. Alternation of responses was the task, so response biases favoring one response over another could produce repetition of the same response and a preponderance of errors for trials on which memory fails.

\section{References}

MORIN, R. E., \& FORRIN, B. Response equivocation and reaction time. J. exp. Psychol., 1963, 66, 30-36.

TUNE, G. S. A brief survey of variables that influence random-generation. Percept. mot. Skills, 1964, 18, 705710 .

\section{Note}

1. This study was supported by National Science Foundation Grant GB-1600 awarded to the first author and Kent State University. 